\title{
A CORRIDA PELA ALTA PERFORMANCE: CONVERGÊNCIAS ENTRE ESPORTE, TRABALHO E CONSUMO NOS DISCURSOS MIDIÁTICOS ${ }^{1}$
}

\author{
LA CARRERA DE ALTO RENDIMIENTO: CONVERGENCIAS ENTRE EL \\ DEPORTE, EL TRABAJO Y EL CONSUMO EN EL DISCURSO DE LOS \\ MEDIOS DE COMUNICACIÓN
}
THE RACE FOR HIGH PERFORMANCE: CONVERGENCES BETWEEN SPORT, WORK AND CONSUMPTION IN MEDIA DISCOURSE

Julia Salgado

UFRJ

juliasalgado@gmail.com

Daniel Portugal

UFRJ

dp@formaelementar.com

\section{Resumo}

Este artigo tem o objetivo de analisar discursos biográficos (especialmente a autobiografia de Abilio Diniz), corporativos e midiáticos que promovem a prática de exercícios físicos (em especial a corrida) como benéficas ao indivíduo-trabalhador. Procuramos compreender algumas conexões estratégicas que se formam nos discursos, como a associação entre os bemestares físico e mental: a corrida ajudaria a aliviar o estresse e a ansiedade acumulados pela atividade laboral. Numa lógica medicalizante, busca-se remediar os efeitos de um trabalho inevitavelmente estressante, sugerindo implicitamente que ele pode conviver em harmonia com o ideal do gozo - desde que se tenha acesso a objetos técnicos ou a práticas terapêuticas variadas. Também é digna de nota a importância dada ao suposto ganho cognitivo que os praticantes têm ao transportar aprendizados do universo do esporte para as esferas profissionais e pessoais. Finalmente, atentamos para as relações emergentes entre a prática de corrida e o consumo contemporâneo.

Palavras-chave: corrida, mercado de trabalho, mídia.

\footnotetext{
${ }^{1}$ Trabalho apresentado no GT Comunicação, consumo, trabalho e espacialidades do II Comunicon (Congresso Internacional em Comunicação e Consumo), realizado em São Paulo nos dias 15 e 16 de outubro de 2012.
} 


\begin{abstract}
This article aims to analyze biographical (specially the autobiography of Abilio Diniz), corporative and media speeches that promote the practice of physical exercises (specially running) as beneficial to the fellow worker. We seek to understand some strategic connections formed in those discourses, as the association between physical and mental well-beings: running is supposed to help relieving stress and anxiety accumulated during labor activity. Within a medicalized logic, the effects of an inevitably stressful work are seen as something that can be overcame by means of medical treatment, implicitly suggesting that it may live in harmony with the ideal of enjoyment - as long as one has access to varied technical objects or therapeutic practices. Also noteworthy is the importance given to the supposed cognitive improvement originated in the transporting of lessons from the sport universe to the professional and personal spheres. Finally we look at the relationships between the emerging practice of running and contemporary consumption.
\end{abstract}

Key words: running, labor market, media.

\title{
Resumen
}

Este artículo tiene como objetivo analizar los discursos biográficos (especialmente la autobiografía de Abilio Diniz), de los negocios y de los medios de comunicación que promueven lo ejercicio físico (especialmente correr) como beneficioso para el individuo de trabajo. Buscamos entender algunas conexiones estratégicas que se forman en los discursos, como la asociación entre los bienestares físicos y mentales: el correr ayudaría a aliviar el estrés y la ansiedad acumulados por la actividad laboral. Dentro de una lógica medicalizada, se busca remediar los efectos de un trabajo inevitablemente estresante, sugiriendo implícitamente que el puede vivir en armonía con el ideal de placer - siempre se tiene acceso a los objetos técnicos o prácticas terapéuticas variadas. También es destacable la importancia que se da a lo supuesto gano cognitivo que los profesionales tienen de transportar de un aprendizaje de el universo del deporte para el ámbito profesional y personal. Por último nos fijamos en las relaciones entre la práctica de carreras y el consumo contemporáneo.

Palabras-clave: rendimiento, raza, mercado laboral, medios de comunicación.

\section{Introdução}

Se no Brasil correr e malhar dá mais disposição para o trabalho, uma pesquisa realizada ao longo de 20 anos em corporações do mundo todo mostra que empregados que praticam esporte também ajudam a engordar os cofres das empresas. O Bank of America percebeu um retorno de U\$6 para cada U\$1 investido em seu programa de promoção de saúde. E a PepsiCo constatou que seu programa de fitness produziu um retorno de $300 \%$ do investimento. (O Globo, 29 jun. 2003)

\section{ANIMUS


Os argumentos contidos no trecho acima dão conta de sensibilizar um dos aspectos mais caros ao empresariado mundo afora: seu bolso. Convencidos de que o estímulo a hábitos saudáveis e à prática de exercícios físicos pelos funcionários é capaz de trazer retornos em termos de produtividade e lucro, líderes de diversas empresas vêm implementando programas de qualidade de vida através dos quais os empregados passam a ter acesso à prática de exercícios físicos (tais como academias de ginástica, grupos de corrida, aulas de yoga etc.) e a informações e cursos (sobre alimentação, estilo de vida, consumo etc.), todos tidos como importantes à qualidade de vida. Objetivos utilitários (como os já mencionados aumento da performance e do lucro) se mesclam a objetivos afetivos e simbólicos (união da equipe, bemestar e saúde do funcionário), formando um discurso corporativo que se constitui como um benefício ao funcionário, uma suposta ação altruísta da empresa preocupada com a satisfação e a felicidade de seus colaboradores.

Mas o discurso corporativo não é, nem de longe, o único a entoar salvas de louvor à prática esportiva entre trabalhadores. A mídia, agindo num ciclo que consiste em alimentar crises de referência para, logo em seguida, oferecer caminhos de suposta transposição dessas crises, recorrentemente aborda o assunto em tons pedagógicos, fazendo uso de recursos já bem conhecidos: divulgação de pesquisas científicas que, embora geralmente dúbias e inconclusivas, supostamente atestam os benefícios da prática de exercícios físicos ao ser humano; declarações de autoridades e especialistas no assunto, além dos gurus e experts midiáticos; depoimentos e relatos de indivíduos comuns, mas que geralmente são escolhidos pelos exemplos edificantes que representam. Além da "mídia oficial", o culto à performance esportiva também invade outra mídia: as páginas das biografias e autobiografias de homens de sucesso que relatam, através de seus exemplos reais, como a prática do esporte os ajudou a vencer nos negócios e na vida. ${ }^{2}$ Nesta rede de discursos múltiplos, porém muitas vezes convergentes, é possível perceber algumas conexões estratégicas que se formam.

A primeira delas diz respeito à associação entre os bem-estares físico e mental: a prática de esportes ajudaria a liberar o hormônio cortisol, em teoria responsável por aliviar o

\footnotetext{
${ }^{2}$ Um influente exemplo nacional de tal subjetividade empreendedora e esportiva - além de Abilio Diniz, cuja biografia analisaremos neste artigo - é Eike Batista, que relata em sua autobiografia $O X$ da questão: "Gosto de praticar esportes, correr, nadar. Sou apaixonado pela velocidade, por carros e lanchas. Fui campeão brasileiro, americano e mundial de offshore. Em 2006, conclui a travessia das 220 milhas náuticas entre Santos e Rio de Janeiro em 3h01min47s, recorde mundial até hoje não superado.” (BATISTA, 2011, p. 19).
} 
estresse e a ansiedade acumulados pela atividade laboral. Numa lógica medicalizante ${ }^{3}$, típica da cena contemporânea, busca-se remediar os efeitos de um trabalho inevitavelmente estressante $^{4}$, sugerindo implicitamente que ele pode conviver em perfeita harmonia com o ideal do gozo - desde que se tenha acesso a objetos técnicos ou a práticas terapêuticas variadas. Associada a esta primeira conexão, é notável, em diversos discursos, a importância dada ao suposto ganho cognitivo que os praticantes têm ao transportar um aprendizado do universo do esporte - como a superação de limites, a tenacidade diante dos desafios, o planejamento de metas, o gosto pela vitória - para as esferas profissionais, pessoais e sociais. Finalmente, é relevante perceber que tal movimento de valorização da atividade física se reflete nas arenas de consumo, uma vez que seus praticantes tornam-se um novo mercado de nicho - especialmente se pensarmos nos corredores, cada vez mais ávidos a consumir a experiência que é participar de uma maratona (e, obviamente, todos os recursos necessários para isso).

Este artigo tem o objetivo de analisar alguns discursos corporativos, midiáticos e autobiográficos que promovem a prática de exercícios físicos (em especial a corrida), atentando sempre para os "implícitos e subentendidos, as brechas da linguagem" (CASAQUI, 2011, p. 200). Exaltada em suas vantagens e facilidades, a prática de corrida vem se mostrando cada vez mais visível ao transbordar as espacialidades privada e corporativa, invadindo ruas e parques das cidades com os grupos de corrida empresariais - que levam as marcas de suas empresas, no peito, para as corridas do dia-a-dia e das competições. Para imprimir um corte analítico importante, propomos examinar diversos discursos sociais de estímulo à corrida tendo como fio condutor a autobiografia de Abilio Diniz, Caminhos $e$

\footnotetext{
${ }^{3}$ Ao falar em "logica medicalizante" queremos fazer referência ao novo estatuto moral da saúde (incluindo a "saúde mental") como bem a ser compulsoriamente perseguido pelos sujeitos através de meios tecnomédicos diversos. O caráter compulsório da moral medicalizante pode ser constatado por qualquer pessoa acima dos quarenta anos que decida não fazer check-ups periódicos, exercícios físicos, dieta ou utilizar medicamentos preventivos - não apenas o indivíduo em questão provavelmente se sentirá culpado por não fazer nenhuma dessas coisas, como seus amigos e familiares provavelmente não se cansarão de "aconselhá-lo" enfaticamente a mudar suas atitudes. Tal "lógica medicalizante" seria mais ampla que o processo de "farmaceuticalização" da medicina e, especialmente, do tratamento psíquico. Para uma reflexão mais detalhada sobre farmaceuticalização, ver o artigo A felicidade é química e pode ser vendida? (PORTUGAL; VAZ, 2012). Interessa observar, de todo modo, a íntima conexão entre a noção de que o tratamento psíquico deve ser realizado, cada vez mais, pela administração de medicamentos e a noção de que a corrida e outros esportes deixam as pessoas mais felizes devido à liberação de endorfina ou outros hormônios (veremos adiante como tal noção aparece frequentemente em diversos enunciados contemporâneos), pois o pressuposto de fundo das duas noções é a de que um estado subjetivo pode ser reduzido a substratos materiais manipuláveis.

${ }^{4}$ Questionar o porquê de um trabalho inevitavelmente estressante não parece estar na pauta da grande mídia, dos livros de autoajuda ou autobiografias.
} 
Escolhas (DINIZ, 2004), na qual o executivo do maior grupo varejista brasileiro - e ferrenho praticante de esportes - dá a sua receita de “equilíbrio para uma vida mais feliz". Mais do que um escrito puramente autobiográfico, trata-se de um misto de textos biográfico, de autoajuda e manual de condução. Algo como um guia de vida, no qual o autor faz uso de sua trajetória, recheada de percalços e superações, para construir-se historicamente como exemplo e, com isso, "ajudar mais gente a seguir a trilha da felicidade" (idem, p. 14). As demais referências, extraídas de revistas, sites, jornais, foram utilizadas apenas na medida em que nos permitiam generalizar para a grande mídia algumas orientações discursivas presentes na autobiografia de Abilio Diniz. O único critério na seleção de tais referências, além da sua compatibilidade discursiva com nosso referencial condutor, foi temporal - utilizamos apenas referências publicadas já no século XXI.

Usar uma biografia como fio que conduz a análise de múltiplos discursos de estímulo à prática esportiva entre trabalhadores justifica-se pela semelhança da retórica utilizada nessas obras (autobiográficas) e na grande mídia. Tendo geralmente indivíduos singulares como exemplos de subjetividade e práxis ideais, esses discursos constroem uma trajetória de aprimoramento pessoal calcado em modelos exteriormente prescritos, e não internamente emergentes. Assim, as escritas de si - para utilizar o termo de Foucault (1992) contemporâneas não parecem ser o lugar de fermentação de uma inquietação produtiva, capaz de gerar um genuíno aperfeiçoamento pessoal, mas tão somente a plataforma de exposição de vitórias e sucessos conquistados, o suporte que demonstra a própria superação. O recurso de encorajar uma prática a partir de exemplos reais de sofrimento, superação e sucesso - tônica comum às autobiografias de grandes empresários, como Abilio - invade as reportagens de revistas, jornais e programas de TV. Impossível resistir à paródia e não sugerir que os modelos ali expostos transformam-se em auspiciosos "caminhos para as escolhas" dos indivíduos.

\section{Sofrimento, superação e sucesso}

Tenho tido sucesso. Claro que sim. Mas meu caminho foi repleto de dificuldades e o êxito só foi alcançado com determinação e disciplina. Não me queixo. Tenho certeza de que o crescimento do ser humano é muito maior no sofrimento do que na felicidade (idem, p. 12). 
Desta maneira, Abilio Diniz justifica, logo nas primeiras páginas de sua autobiografia com tonalidade de texto de autoajuda, o motivo que o levou a publicar um livro. No alto de seus 68 anos (na ocasião de lançamento do livro; hoje ele tem 75), Diniz argumenta ter passado - e superado - experiências negativas suficientes para fazer dele uma espécie de conselheiro de vida. Seus leitores teriam a oportunidade de aprender com seus erros e, assim, sofrer menos. Paradoxalmente, o homem que não acredita em crescimento pessoal sem alguma dose de sofrimento oferta a seus leitores um caminho de redenção e êxito privado de penúrias.

A história narrada por Abilio relata um período de aproximadamente sessenta anos (dos 8 aos 68 anos) pontuado por dois marcantes momentos de superação. O primeiro acontece por volta dos 12 anos, quando o filho de padeiro "baixinho, gordinho, filho único até os 7 anos" passa de presença invisível numa escola a alvo de escárnio e agressões físicas em outra. A primeira superação a se fazer teria origem no bullying sofrido na infância, no colégio Anglo-Latino: "Não me lembro exatamente como, mas foi naquela época que tomei uma decisão: nunca mais voltaria a apanhar de ninguém. Jamais voltaria a me acanhar diante das ameaças que sofresse. Dali em diante, quem me ameaçasse receberia o troco” (idem, p. 26)

A partir desta primeira "metamorfose", na palavra do próprio executivo, emergiu um novo sujeito, pleno em autoestima, autoconfiança, mas também certo distanciamento afetivo. "Passei a me admirar e, mais do que isso, a me considerar indestrutível. Ao mesmo tempo, me tornei introspectivo e distante das pessoas. Cada vitória me tornava um pouco mais autosuficiente [sic]" (idem, p. 27). O texto segue elencando as conquistas profissionais e esportivas adquiridas ao longo da juventude e fase adulta ${ }^{5}$. Economista, empreendedor e executivo de uma grande rede varejista, membro do Conselho Monetário Nacional; tricampeão de motonáutica, vice-campeão de automobilismo e de levantamento de pesos, ferrenho praticante de futebol, corrida, natação, polo, ciclismo... O menino que havia superado o excesso de peso e a hostilidade alheia se tornava um pleno vencedor, encarnando o modelo maior de sucesso contemporâneo: empreendedor de sucesso e também esportista de alta performance. Segundo ele, sua arrogância e intolerância aumentavam à mesma proporção de seus êxitos e vitórias.

\footnotetext{
${ }^{5}$ Muito pouco é falado da sua vida pessoal e das conquistas afetivas. 
Ao final da década de 1970 seu pai decide repartir, quase igualmente, a rede de supermercados entre os herdeiros. Descontente com a decisão ${ }^{6}$, Abilio se afasta do grupo e passa a dividir seu tempo entre a administração do seu quinhão nos negócios e o novo trabalho como membro do Conselho Monetário Nacional, em Brasília. Esse era o primeiro indício de uma leva de sofrimentos e dificuldades que o conduziria à segunda grande superação de sua vida. O "racha" na família, causado pelas discussões sobre o comando da empresa, seria seguido de seu sequestro, em dezembro de 1989. Aos sete dias de cárcere num cubículo subterrâneo se somaria, ainda, o quase falimento do Grupo Pão de Açúcar, em 1990. Estes três penosos acontecimentos - briga familiar, sequestro e iminência de uma bancarrota seriam os insumos para uma segunda transformação pessoal, agora muito mais profunda e duradoura:

Humildade. Essa é a palavra-chave em torno da qual se organiza todo o processo de mudança pelo qual passei nos últimos anos. Nada disso, claro, aconteceu de uma hora para outra. Não houve uma noite mágica em que fui dormir arrogante para acordar humilde. Foi um processo de aprendizado longo e muitas vezes doloroso. [...] Um processo de busca do autoconhecimento e da construção de uma auto-estima [sic] diferente daquela que experimentei quando me tornei bom de briga. É justamente esse processo de mudança e de melhoria da qualidade de vida que eu pretendo tratar nesse livro. [...] A intenção neste livro é compartilhar com as pessoas as lições que aprendi após superar momentos de extrema tensão (idem, p. 43-44)

Superação, como se percebe, é a tônica do livro. Nesta e em outras construções discursivas $^{7}$, a superação é, quase invariavelmente, precedida de algum sofrimento ou dificuldade do indivíduo. Os vieses da vida atuariam, assim, como propulsores à atitude de superação que, por sua vez, quando bem empreendida, tem grandes chances de resultar em sucesso. Em enunciações que trazem a marca de um "ascetismo leigo" próximo daquele identificado por Weber (2004), legitima-se a noção de que o caminho para o sucesso deve ser árduo e penoso, repleto de provações e superações: sofrer, portanto, é importante; superar-se é indispensável. O elemento responsável por transformar sofrimento em superação - e, com

\footnotetext{
6 "O fato de eu ter dado o sangue pela empresa e de ter contribuído muito mais do que qualquer um de meus irmãos para a expansão do Pão de Açúcar não me conferia qualquer vantagem dentro da sociedade” (DINIZ, 2004, p. 33).

7 "Superação pessoal e GATORADE são os combustíveis perfeitos para a melhor experiência durante a prova", diz trecho do publieditorial da Gatorade na revista Maratona Caixa da Cidade do Rio de Janeiro, distribuída em julho de 2012, como forma de promover o evento.
} 
isso, alcançar o sucesso - é, segundo Abilio e diversos discursos midiáticos, a disciplina. A disciplina, "força que nos impede de desviar do caminho que traçamos para nós mesmos" (DINIZ, 2004, p. 50), seria elemento indispensável para transformar um modo de vida errante e ocasional em uma trajetória predeterminada à vitória e ao sucesso.

No relato de Abilio, o ímpeto para superar o bullying e a baixa autoestima veio predominantemente do esporte - um esporte que enquanto tonificava o corpo, afiava o perfil competitivo necessário ao mundo dos negócios. A segunda e mais recente superação envolveu outros fatores além da performance física. Os traumas pessoais, familiares e financeiros o teriam feito refletir a respeito de sua existência, e assim chegar a seis elementos, segundo ele complementares entre si e essenciais à qualidade de vida:

Percebi, ao longo desse processo, que a vida pode ser muito melhor quando conseguimos levar em conta seis fatores - todos eles essenciais.

Os três primeiros dizem respeito à saúde física. Nossa possibilidade de protegê-la e de reforçá-la aumenta muito a partir do instante em que passamos a nos dedicar a uma atividade física regular e bem orientada; do momento em que olhamos com mais atenção para aquilo que comemos e para a forma de nos relacionar com os alimentos; e, finalmente, da hora em que nos damos conta de que uma série de fatores causadores do stress estão (sic) inteiramente sob nosso controle. Cabe a nós mantê-los à distância.

Os outros três fatores dizem respeito à maneira de nos colocar no mundo. $\mathrm{O}$ primeiro deles é o autoconhecimento, a importância de estarmos sempre olhando para dentro de nós mesmos; o segundo é o amor, um sentimento que traz muito mais benefícios, e que deve ser muito mais praticado do que o ódio; o último trata da importância e da necessidade de nos relacionarmos com a grande força ordenadora do universo - Deus - por meio da fé e da espiritualidade (idem, p. 48-49).

A partir daí o livro assume definitivamente a forma de um manual de conduta pragmático e espiritual, com cada um dos seis elementos protagonizando um capítulo diverso. Ao final, o leitor é ainda contemplado com o Manual do Abilio, guia recheado com programas, planilhas, tabelas e dicas que vão do treinamento físico ao espiritual, da alimentação ideal ao controle de estresse. Destrinchar todo o conteúdo do livro - ainda que uma tarefa tentadora - não é o objetivo deste artigo. Mas fazendo, a partir daqui, a ponte com os discursos corporativos e midiáticos, interessa-nos compreender as relações estabelecidas entre a prática de exercícios físicos (a corrida, em especial) e o desempenho profissional.

\section{Desempenhos físico e profissional}


Falo de esporte com entusiasmo porque ele sempre foi para mim, desde a adolescência, uma fonte de bem-estar e alegria. Mais até: foi um instrumento que me ajudou a moldar uma auto-estima [sic] tão firme quanto minha musculatura. (idem, p. 61).

$\mathrm{O}$ primeiro dos seis fatores essenciais à qualidade de vida, segundo Abilio, é a atividade física. No capítulo dedicado a ela o empresário descreve como a prática intensa de exercícios físicos foi importante, e mesmo necessária, para ele se tornar o homem que é. A descrição dos prazeres obtidos com o esporte nos faz imaginar um interlocutor viciado pelas sensações provenientes da liberação de endorfina - algo que se repete em muitos relatos midiáticos de praticantes de esportes ${ }^{8}$. A "droga esportiva” não estaria em dissintonia com as demais drogas contemporâneas, que mais do que propiciar experiências de introspecção, como naquelas da década de 1960, ofertam aumento de performance e ostentação de si. Mas o vício, aqui, ganha conotação inteiramente positiva: suas mais de três horas diárias de exercício $^{9}$ são objeto de orgulho para ele e de admiração para seus funcionários, que pontuam seu texto com depoimentos. Como o da secretária executiva Sonia Ponzini: "Posso dizer que minha mudança de vida se deu porque fui influenciada por ele [Abilio] e pelo seu exemplo. Via o quanto ele era disciplinado, como conseguia manter suas rotinas de treinos diários e pensei: "Vou fazer também"” (idem, p. 78). Ou do garçom da diretoria do Pão de Açúcar, Irenaldo Cunha: “Se ele leva a sério, quem sou eu para não levar também?” (idem, p. 78).

O questionamento do garçom exemplifica bem a construção subjetiva erguida em torno de empresários e esportistas de alto rendimento, como Abilio Diniz. Isso porque ele encarna a figura do empresário de sucesso, rico e bem de vida, mas que nem por isso deixa de ser incansável no trabalho - prova disso é ter reerguido o Pão de Açúcar das cinzas, devolvendo-o o posto de maior grupo varejista do país. Como ele mesmo diz em seu livro,

\footnotetext{
8 “[...] o bem-estar que invade nosso corpo após o exercício cumprido e que, desde então, não conseguem mais viver sem ele" (Diniz, 2004, p. 58). "De todos os vícios que eu tenho - fumo, café, comida, sexo - [a corrida] é o único que me faz tão bem" (narração do programa GloboNews Saúde de 05 jun. 2012, um de uma série dedicada à prática de corrida. Disponível em: <http://g1.globo.com/globo-news/saude/videos/t/todos-os-videos/v/corridaoferece-riscos-e-beneficios-a-saude-do-praticante/1979693>. Acesso em: 22 jun. 2012). "Quando cheguei ao Km 19, comecei a sentir os efeitos da endorfina! Fiquei pilhada, eufórica, feliz! Olha, gente... nunca experimentei nenhuma substância ilícita na vida, mas confesso que nesse momento achei que estava na maior onda!! Ria por nada e por tudo!" (depoimento de uma atleta amadora sobre sua participação na Maratona do Rio no blog Pulso, do Globo. Disponível em: <http://oglobo.globo.com/blogs/pulso/posts/2011/07/20/maratona-do-rio-depoimentode-eugenia-del-vigna-guga-393521.asp>. Acesso em: 28 jul. 2012.

${ }^{9}$ Sua prática diária de exercícios é dividida em três períodos: uma hora de atividades aeróbias antes do café da manhã; 45 minutos de musculação e alongamento antes do almoço e mais de uma hora de algum esporte de competição, como o squash, antes do jantar.
} 
poderia ter pensado como tantas outras pessoas e desistido, abandonado tudo, seguido outro caminho - o que certamente, com os seus contatos, não seria tarefa difícil. Mas em tons nada humildes, ele contesta essa alternativa: "Não quero parecer o Super-homem, mas, com toda sinceridade, minha cabeça funcionou na direção oposta à das pessoas que tinham esse tipo de opinião" (idem, p. 64). Assim, essa personificação da resiliência, disciplina e perseverança - o empresário bem sucedido que, com muita disciplina, administra uma agenda atribulada e um trabalho estressante com uma dedicação quase religiosa ao exercício físico - serve de exemplo para os quase 150 mil funcionários do Pão de Açúcar ${ }^{10}$. Encarnando - por que não? - a "figura de [re]começo" (EHRENBERG, 2010), aquele capaz de "fazer-se a si mesmo" (idem, p. 53) independente de sua origem ou herança, Abílio é uma demonstração do possível, o empresário de sua própria vida, empreendendo no trabalho e no corpo. Para ele, há uma estreita relação entre as duas esferas.

A lógica desta relação é a de que os exercícios resultam em ganhos não apenas físicos, mas também psíquicos - "uma partida de squash ou de qualquer outro esporte de competição tem o poder de tirar da cabeça as preocupações e as tensões naturais do trabalho" (DINIZ, 2004, p. 69-70, grifo nosso) - e cognitivos - "O esporte ensina. Competir, treinar arduamente, sofrer com as derrotas, superar os maus resultados. Essas experiências têm um impacto profundo na formação de uma pessoa" (O segredo dos campeões, Revista Você S/A, 05 jan. 2010). Assim, contribuiriam para o enfrentamento dos mal-estares e das dificuldades provenientes do trabalho árduo. Numa prática já constante de nossa sociedade contemporânea, não há qualquer questionamento do por que ou da necessidade de um trabalho que cause tanto estresse. Ao invés disso, lança-se mão do esporte como um remédio - talvez mais saudável do que ansiolíticos, antidepressivos e tranquilizantes, mas que não deixa de ser apenas um paliativo, um atenuante diante de uma rotina de trabalho que, como se percebe, é naturalizada como devendo ser cada vez mais intensa (BOLTANSKI; CHIAPELLO, 2009).

Não questionar a existência - e a permanência - de um mercado de trabalho essencialmente desgastante ao indivíduo não impede o empresário de se orgulhar em dizer que sua "companhia é uma das empresas brasileiras que mais reconhece a importância da atividade física na vida de seus colaboradores" (DINIZ, 2004, p. 60). Obviamente, os

\footnotetext{
${ }^{10}$ E agora, também, aos alunos do curso de "Liderança 360 - Abilio Diniz", da FGV/SP, que desde 2010 faz uso da sua história de vida para ensinar conceitos de liderança, negociação, administração do tempo e qualidade de vida. Disponível em: 〈http://gvpec.fgv.br/cursos/lideranca-360-abilio-diniz〉. Acesso em: 27 jul. 2012.
} 
objetivos puramente utilitários do estímulo à prática esportiva - como a diminuição das faltas dos empregados, o consequente aumento da produtividade e os imensos descontos obtidos no seguro de saúde corporativo ${ }^{11}$ - restam apenas implícitos nos discursos corporativos, que exaltam principalmente a associação entre os bem-estares físico e psíquico:

Criado em 1992, quando pouco ou quase nada se falava a respeito de qualidade de vida no mundo corporativo, o Pão de Açúcar Clube, o primeiro clube-empresa do País especializado em treinamento de corrida e caminhada, serve de modelo de referência para outras empresas que resolveram mais tarde adotar programas internos de qualidade de vida para melhorar a saúde de seus colaboradores e combater o sedentarismo. Hoje o programa, que promove treinos de corrida e caminhada regularmente e também atividades como natação e hidroginástica, conta com a participação de 3 mil colaboradores, todos auxiliados por profissionais especializados nas áreas de Educação Física e Nutrição. Além da participação em corridas de todo o Brasil, o clube já marcou presença com seus colaboradores em vários eventos internacionais expressivos, como Maratona de Nova York (sete anos), Maratona e Meia Maratona da Disney (dois anos) e, mais recentemente, Maratona e Meia maratona de Paris (quatro anos). ${ }^{12}$

A corrida de rua, segundo esporte mais popular no Brasil ${ }^{13}$, tornou-se o carro chefe dos programas de exercício físico de grande número de empresas. As razões são bastante simples: é uma atividade barata, que exige parcos investimentos iniciais - os maiores investimentos seriam de ordem comportamental (como disciplina, organização, determinação), e não financeira. É flexível, podendo cada um adequar o treino aos seus horários e disponibilidades. Finalmente é uma atividade acessível a todos à medida que as ruas e os parques públicos são o grande palco de ação. Como resultado, os grupos de corrida de rua, em sua maioria compostos por colaboradores das mais diversas empresas, proliferam país afora. Segundo a reportagem “Como a corrida influencia na carreira?”, publicada na Revista Exame em 12 de julho de 2012:

O esporte tem atualmente cerca de 4 milhões de praticantes no Brasil. Considerando as maratonas, meia maratonas e provas de rua de baixa quilometragem (5 quilômetros, por exemplo), há mais de 600 eventos por

\footnotetext{
${ }^{11}$ Segundo resolução da Agência Nacional de Saúde (ANS), os descontos podem chegar a 30\% do valor do plano. Disponível em: <http://www.ans.gov.br/index.php/a-ans/sala-de-noticias-ans/a-ans/1523-apaixone-se-porvoce> e <http://exame.abril.com.br/brasil/noticias/vida-saudavel-podera-render-desconto-no-plano-de-saude>. Acesso em: 27 jul. 2012.

12 Disponível em: <http://www.grupopaodeacucar.com.br/responsabilidade-socioambiental/qualidade-devida/iniciativas-6.htm>. Acesso em: 27 jul. 2012.

13 Disponível em: <http://www1.folha.uol.com.br/mercado/798420-corrida-de-rua-2-esporte-mais-popular-dobrasil-movimenta-r-3-bi-ao-ano.shtml>. Acesso em: 27 jul. 2012.
} 
ano, 200 deles só na cidade de São Paulo. [...]. A atividade ajuda a amenizar ou controlar fatores como obesidade, estresse, diabetes e colesterol. Correr, enfim, torna o sujeito mais saudável. Há também quem aproveite os treinos e as provas de rua para trocar cartões, captar clientes e até mudar de emprego. ${ }^{14}$

Praticar um exercício físico e ainda implementar o network profissional é o que propõe a Corporate Run $^{15}$, competição realizada há oito anos em São Paulo e há cinco no Rio de Janeiro. Com o mega slogan "Competição saudável, confraternização, network, oportunidades de negócios, saúde, bem-estar e qualidade de vida, energia e bom humor", a corrida reúne equipes empresariais, com quatro funcionários cada, competindo em nome das suas corporações. De grupos de mídia (O Globo, Revista Época, O Dia, Record, Band News, Estado de SP) a bancos e grupos de investimento (Bradesco, UBS, Deutsche Bank, BB Previ, Citi Bank); de montadoras de veículos (Honda, Peugeot/Citroen, Toyota) a indústrias farmacêuticas (Merk, Norvartis, Pfizer); de empresas de grande porte (Vale, Petros, EBX, Coca Cola, IBM) até pequenas organizações (Comlurb, Bope, Grupo dos Fuzileiros Navais, Metrô Rio). Em 2011, a etapa do Rio de Janeiro reuniu mais de 6 mil corredores, enquanto em São Paulo cerca de 9 mil correram por suas empresas. Para estimular a "competição saudável”, o site do evento ainda oferece a oportunidade das equipes travarem desafios entre si. Os inscritos podem, assim, desafiar outra equipe de sua própria empresa ou também uma equipe de empresa alheia, transformando a disputa interna entre equipes em mais uma fonte de superação de limites, competição e conquista de vitória para os participantes.

Isso nos leva a outro ponto interessante que emerge na análise dos discursos que relacionam a prática esportiva à alta performance profissional: trata-se do tipo de aprendizado obtido nas quadras e nas pistas, e como ele pode ser benéfico ao indivíduo que o transporta para outras arenas da vida, tal qual a profissional ou a pessoal. O comprometimento em praticar um esporte de maneira assídua e diligente demandaria, mesmo do atleta amador, o planejamento e o estabelecimento de metas, um cronograma de tarefas e ações, o desenvolvimento da habilidade de lidar com situações inusitadas, de pressão ou competitividade. Por outro lado, com o progresso esportivo surgiria no indivíduo o gosto pela ação, competição, vitória e superação dos próprios limites. Como é possível perceber, o léxico

\footnotetext{
14 Disponível em: <http://exame.abril.com.br/carreira/noticias/corre-corre-de-negocios>. Acesso em: 26 jul. 2012.

${ }^{15}$ Disponível em: <http://www.corporaterun.com.br>. Acesso em: 27 jul. 2012.
} 
utilizado para descrever as ações esportivas é amplamente similar àquele de derivação bélica que vem sendo empregado no universo corporativo, e, como resultado, os aprendizados do sujeito-esportista servem para empoderar o sujeito-empreendedor (de si, de sua empresa, de seu trabalho). A prática esportiva torna-se, portanto, "um sistema de condutas de si que consiste em implicar o indivíduo na formação de sua autonomia e de sua responsabilidade" (EHRENBERG, 2010, p. 18).

É exatamente o que destaca a matéria "O segredo dos campeões", da revista Você $S / A$, em janeiro de 2010. A partir dos exemplos de ex-atletas profissionais, a reportagem atesta "como a experiência esportiva ajuda a obter alto desempenho na carreira". "Aprender a reagir após uma derrota" - o que os gurus do management chamam de resiliência -; "estar sempre preparado para lidar com o inesperado"; "valorizar uma oportunidade e lutar ao máximo para aproveitá-la", afinal "todo mundo foi reserva e sabe o quanto vale ser chamado pelo técnico. No mundo das empresas, você luta pela oportunidade dessa maneira". Todos esses aprendizados seriam eficazmente aproveitados pelo empreendedor de si, que deve agir no sentido de desenvolver e aprimorar as competências que valorizem seu biocapital, enquanto abandone os hábitos que o depreciem (FOUCAULT, 2008a). Não é preciso, portanto, ser um ex-atleta profissional para obter, na carreira, as vantagens competitivas doutrinadas pelo esporte:

O mundo do trabalho vive uma competição constante, como ocorre no esporte. A diferença, dizem os ex-atletas, é que para praticar esporte de alto desempenho existe o treino diário, que dá força, resistência, confiança e poder de recuperação. No mundo do trabalho, você compete, mas não treina, diz Ricardo. Com isso, você não se recupera de forma adequada, o que faz seu desempenho cair. Para manter-se em alta profissionalmente, faça como os esportistas: treine o corpo e a mente. Você precisa cuidar da saúde para ser executivo, diz Luís Guilherme. ${ }^{16}$

\section{Consumindo a 'experiência maratona'}

O instante em que cruzei a linha de chegada foi, sem dúvida, um dos mais emocionantes da minha vida. Tive a impressão de que tudo o que eu fizera em matéria de esportes, no fundo, no fundo, havia sido apenas uma preparação para aquela conquista. Vitória, essa é a palavra.

\footnotetext{
${ }^{16}$ Disponível em: <http://vocesa.abril.com.br/desenvolva-sua-carreira/materia/segredo-campeoes523652.shtml\#>. Acesso em: 18 jul. 2012.
} 
Independentemente da posição em que eu tenha terminado a prova, eu me sentia um vencedor. E era mesmo (DINIZ, 2004, p. 57).

Desta forma, Abílio Diniz descreve a experiência que teve ao completar sua primeira maratona, a de Nova York de 1994. Momento inesquecível, sensação de euforia, sentimento de vitória. Descrições como esta são cada vez mais comuns em reportagens que falam da participação de atletas amadores em maratonas mundo afora. $\mathrm{O}$ denominador comum aos depoimentos é, novamente, a superação de si. Levar o corpo ao limite durante as mais de quatro horas ininterruptas de corrida, mas mesmo assim dominar os cansaços físico e mental seria o grande barato de uma turma denominada como sendo "da endorfina" ( $O$ Globo, 21 jul. 2012).

Valeu a pena cada treino, cada dor, cada momento de preparação... a sensação de percorrer os 42,2k é realmente uma coisa de outro mundo! Energia positiva, alegria, conquista, superação.. Vale muito a pena!!!! ${ }^{17}$

Cabeça decidida, começa a jornada pelos muitos quilômetros que culminarão nos 175 metros finais e o pórtico de chegada. Emoção e lágrimas compõem o cenário da superação, assim como as bolhas e dores que vão tentar (sem sucesso) tirar a sensação de que você é capaz de tudo. ${ }^{18}$

Depoimentos como estes explicariam não apenas a disseminada dedicação pessoal em comprometer-se com uma atividade que exige tamanhos esforços físicos e psíquicos, mas também os investimentos financeiros que a prática empenha. Não obstante a ubíqua mensagem de que a corrida seria um esporte barato e democrático - demandando tão somente um par de tênis e uma via pública -, surge uma miríade de produtos e serviços à disposição dos corredores obstinados em aprimorar seu desempenho nas pistas. "Esse correcorre movimenta anualmente 4 bilhões de reais por ano (sic), gerando receita para companhias de vestuário, tênis, suplementos vitamínicos e equipamentos para corrida, como relógio." ${ }^{19}$ Mas não é só. Não citada pela reportagem, as viagens para participar de maratonas ao redor do mundo proliferam como novo nicho a ser explorado pelas agências de turismo. Das "maratonas familiares”, como a clássica da Disney, chegando ao disputado quinteto da World

\footnotetext{
17 Disponível em: <http://oglobo.globo.com/blogs/pulso/posts/2011/07/20/maratona-do-rio-depoimento-deeugenia-del-vigna-guga-393521.asp>. Acesso em: 27 jul. 2012.

18 Disponível em <http://revistacontrarelogio.com.br/materia/corra-uma-maratona-voce-vai-sofrer-mas-vaiadorar/>. Acesso em: 26 jul. 2012.

${ }^{19}$ Disponível em: <http://exame.abril.com.br/carreira/noticias/corre-corre-de-negocios〉. Acesso em: 26 jul. 2012.
} 
Marathon Majors (Berlim, Chicago, Nova York, Boston e Londres), o turismo esportivo, e aqui especificamente aquele voltado a maratonas, cresce vertiginosamente no Brasil.

Os pacotes mais "em conta", como os que têm destinos nacionais ou na América do Sul, não saem por menos de mil reais. Já os suprassumos dos maratonistas (Berlim, Boston, NY e Londres) chegam a custar dez mil reais - valor obviamente facilitado pelos benefícios do crédito parcelado. As ofertas de viagens para participar de uma maratona se multiplicam e diversificam, com destinos exóticos como Mumbai, Seul e Ilha de Páscoa. Tudo para agradar o praticante que aqui se transforma em consumidor de experiência. No texto de apresentação oficial da Maratona da Disney ${ }^{20}$ (tradução nossa), por exemplo, lemos:

Imagine um fim de semana de corridas em que cada milha está repleta de 'diversão Disney'. Junte-se a nós para um fim de semana de corridas mágicas e memoráveis [...] que percorre os quatro parques temáticos da Disney. Complete tudo com amigos e medalhas de Mickey Mouse. Você seria, bem, um 'pateta' em perdê-la!

Estimulado social e profissionalmente a inserir a prática de corrida em sua vida, o indivíduo que se transforma em atleta amador não escapa à interpelação do consumo. Se pudermos pensar, portanto, em toda esfera criada em torno da corrida como um grande dispositivo de poder - que produziria corpos disciplinados e cada vez mais produtivos - , tal dispositivo teria como efeito (ou como consequência do "processo perpétuo de preenchimento estratégico", na formulação de Foucault, 2008b, p. 245) o consumo, eficaz em reutilizar afetividades, desejos e emoções germinadas na prática da e no discurso sobre a corrida para estimular a venda de bebidas tônicas, roupas, tênis, relógios e viagens. Assim, o trabalho, que serviu como propulsor à prática de corrida, pode aparecer também como a condição de sua possibilidade, como afirma o médico Paulo Rodrigues à revista Pulso, encarte do Globo dedicado à corrida: "O esporte só não é mais importante do que o trabalho na minha vida porque é ele [trabalho] que sustenta o esporte" (Pulso, O Globo, 23 mar. 2012) ${ }^{21}$.

\section{Conclusão}

\footnotetext{
${ }^{20}$ Disponível em <http://espnwwos.disney.go.com/events/rundisney/wdw-marathon>. Acesso em: 31 jul. 2012.

${ }^{21}$ Disponível em: <http://oglobo.globo.com/blogs/pulso/posts/2012/03/23/revista-pulso-ele-se-reinventou-aposos-40-437369.asp>. Acesso em: 31 jul. 2012.
} 
Transformada em atividade física da moda pela imensa popularidade que agrega, a corrida de rua vem sendo absorvida, nas duas últimas décadas, pelo universo empresarial. A facilidade de sua prática e a visibilidade de marca que proporciona são, juntamente com o aumento de lucro e produtividade e a redução dos custos em seguros médicos, os motivos que levam diversas empresas a investirem nos grupos de corrida como benefícios de um plano de qualidade de vida corporativo. Os discursos de sua promoção - sejam eles corporativos, midiáticos ou pessoais - insistem em apresentar a prática de corrida como panaceia aos problemas naturalmente decorrentes de um mercado de trabalho positivamente legitimado como competitivo, estressante e incessantemente desafiador ao sujeito. A superação de si aprendida nas pistas passa a ser, hoje, indispensável ao indivíduo intencionado a sobreviver num mercado de trabalho cuja única certeza está na constante competição.

\section{Referências}

BATISTA, E. O X da questão. Rio de Janeiro: Sextante, 2011.

BOLTANSKI, L.; CHIAPELLO, E. O novo espírito do capitalismo. São Paulo: Martins Fontes, 2009.

CASAQUI, V. Trabalho, consumo e a produção da felicidade. In: FREIRE FILHO, J. e PINTO COELHO, M.G (orgs.). A promoção do capital humano: mídia, subjetividade e o novo espírito do capitalismo. Porto Alegre: Sulina, 2011.

DINIZ, A. Abilio Diniz, caminhos e escolhas: o equilíbrio para uma vida mais feliz. Rio de Janeiro: Elsevier, 2004.

EHRENBERG, A. O culto da performance. São Paulo: Idéias \& Letras, 2010. FOUCAULT, M. O nascimento da biopolítica. São Paulo: Martins Fontes, 2008a.

Microfísica do poder. Rio de Janeiro, Graal, 2008b.

. A escrita de si. In: O que é um autor? Lisboa: Vega, 1992.

PORTUGAL, D.; VAZ, P. A felicidade é química e pode ser vendida? As dimensões éticas e mercadológicas da razão farmacêutica. In: Encontro Anual da Compós, jun. 2012, Juiz de Fora. Disponível em: 〈http://www.compos.org.br/data/biblioteca_1843.doc〉. Acesso em: 25 nov. 2012.

WEBER, M. A ética protestante e o espírito do capitalismo. São Paulo: Companhia das letras, 2004 
Original recebido em: 30/10/2012

Aceito para publicação em: 03/12/2012

Resumo do Autor

Julia Salgado é Mestre em

Comunicação e Cultura pela Escola de Comunicação da UFRJ. Atualmente é Doutoranda pela mesma instituição, na linha de pesquisa Mídias e Mediações Socioculturais.

Daniel Portugal é Mestre em Comunicação e Práticas de Consumo pela ESPM/SP. Atualmente é Doutorando em Comunicação e Cultura pela Escola de Comunicação da UFRJ, pela linha de pesquisa Mídias e Mediações Socioculturais. 